\title{
SOME SOURCES OF ERROR IN AN ESTIMATE.
}

\author{
By G. A. Mulloy
}

Estimates of standing timber are constantly being made by governments, operating companies and private survey organizations. The intensity and cost of these surveys vary with the purpose for which they are intended and it should be recognized that only what is paid for is obtained. If a general stock-taking survey, which is to be used as a basis for sale or exchange of a property, has been made, it cannot be expected to form the basis later for local allocation of cutting by jobbers. This principle should be explained thoroughly to the management of any company by the forester so that there will be no misunderstanding at a later date. In other words the management should be warned that a cheap article is fully limited by its cheapness. It may often pay to make a larger expenditure at the beginning than to make a complete new survey, which must be done if a more intensive estimate is required.

However, where a fairly intensive survey and estimate has been made which is intended for use as a basis for locating jobbers, there are several factors which possibly may affect the accuracy of the estimate for a small block of timber. It will always be necessary for the forester in charge to look over the particular block of timber to obtain an idea of probable accuracy of the original estimate. A check survey may be necessary for each individual operation. The reason for this is that in compiling the data of the original survey averages are used throughout in the stock or stand table, the diameter-height curves and the volume tables. Whether these averages can be used or not for the particular area depends on whether the same average conditions obtain. Then again, the forester must ascertain whether the utilization factors used in the original calculations actually tally with the conditions of utilization in the district. Heights of stumps, top diameter and scaling and logging practice may all seriously affect the accuracy of the original estimate. Some of the most common sources of error, the method of estimating their effect on the estimate and means of eliminating or adjusting them will be dealt with hereunder.

\section{STAND OR STOCK TABLE}

The usual practice in forest survey is to build up an average stand or stock table for a distinct type or large block. But this is not always the case. Some operators make their estimates by measuring plots evenly distributed over the area and on each of which the actual volume per acre is calculated. In the former case the average stand table is the basis for the volume calculation of the type or large block and in the latter case the average volumes on particular plots form the basis for this calculation. The advantages and disadvantages of these two measures is outside the scope of this article. But in either case the resultant average may not be truly applic- 
able to the small block for which a separate estimate is made, the reason for this being that the strips or line-plots may not have been run close enough together to catch small pockets of strips of denser or lighter timber on the block. While this condition should not affect the estimate on large blocks, as a true average is probably assured by the quantity of strips or plots taken, it would greatly affect the estimate on a small area. The block must be examined to ascertain if the timber runs uniformly enough to allow the original tally to be used. If not, subsidiary strips or plots will have to be recorded. If the original tree tally has been made by means of line-plots, a good check on the uniformity of the stand can be obtained from an exam. ination and comparison of the stands or volumes on these plots.

\section{DIAMETER HEIGHT CURVES}

In all estimates where volume tables based on height are used either as applied to stand tables or to individual plots, it is necessary to have an average diameter height curve for each species on the area. Even if a local volume table based on diameter alone be used, it is based on a particular diameter height curve, which may or may not be applicable to the particular block being estimated although it may be suitable for application for a whole type or large block. Outside of gross errors in calculation, the use of an unsuitable diameter-height curve can cause greater errors than most other factors. Over 40 per cent error in the estimate may be caused by the use of an unsuitable diameter-height curve, as can be seen from the examination of any volume table based on diameter and height; this being the difference between two trees of the same diameter but with 20 feet difference in height. Since height is so greatly influenced by site that it is universally used in site classification, it follows that the particular combination or representation of sites on the block will determine whether the original diameter-height curves are applicable to the smaller area.

The obvious method of determining the presence and magnitude of any possible error owing to this cause is to take enough height measurements on the block to construct new diameter-height curves. If no appreciable difference is found, then this factor can be eliminated as a possible source of error in the estimate. But if quite appreciable differences are found, some adjustment of the estimate will have to be made. Whether it is necessary to do all the work of volume calculation over again will depend upon circum. stances. It may be advisable to do so. But adjustment can be made in the volume of any species by the following method. Find from the volume table by interpolation the percentage difference for each diameter class between the volume of a tree of the height used in the original estimate and the volume for the height from the new diameter-height curve. This will provide factors for adjusting the volume of each diameter class; if a general adjustment percentage is needed, a weighted average may be obtained by weighting the 
adjustment percentage for each diameter class with the number of trees in these diameter classes as found in the stand or stock table. Of course this adjustment may be as much work as to make the whole volume calculation over again for the small block.

\section{FORM CLASS}

If form class tables have been used and the average form-class determined for the various species over the whole type, it will generally be found that the same average form class will obtain on the smaller area. In any event, the error involved here is small. That is, the volume varies only about one to two per cent per unit. So that, unless great accuracy is needed for the estimate on a small block, variation in average form class may be neglected.

\section{UTILIZATION FACTORS AND SCALING PRACTICE}

Estimates are rarely made in total cubic feet per acre except for scientific investigation. They are made either in cubic feet or cords of merchantable timber, or board feet in certain rules. The volume table used must be constructed with a certain height of stump and certain top diameter. Whether these conditions tally with the utilization conditions that will obtain on the block in question must be determined.

The difference of one half foot in the actual average stump height and the stump height on which the volume table has been compiled may account for quite a perceptible error, especially if the estimate is in cubic feet or cords of merchantable material.

The top diameters used in the volume table construction should be the same as the jobber will use in the cutting of the block. This factor will make some difference in cubic feet, and in board feet it will make a large difference.

It is with the length of logs, however, that discrepancies of an important nature may obtain. If the volume table in board-feet which was used has been constructed with sixteen foot logs as a basis and twelve foot logs are cut, errors of 15 to 20 per cent in magnitude may occur owing to this factor alone, as it is quite possible using some of the board foot rules, to cut 4 feet from the small end of a 16 foot $\log$ and yet have the resultant 12 foot $\log$ scale more than the original one.

Again there is the factor of scaling practice. For instance when scaling logs, diameters are grouped in inch classes, the general practice being to accept the half inch point as the dividing line between inch classes. But in some provinces 0.75 of an inch and under is taken as a unit, while in others the even inch is taken as the dividing point i.e. 10.9 inches is recorded as 10 inches. These conditions must be considered when selecting the volume table and in tallying diameters in the field as an error of from 8 to 10 per cent in volume may be caused by this factor alone.

Again, if cull factors are used in the scaling, quite a large discrepancy 
between the estimate and the actual scale may result. Possibilities of error in this direction should be considered and adjustments made accordingly.

These various factors of utilization and scaling practice will in all probability affect the estimate on the whole type or area as well as on the small block. This indicates that in making the original estimate the utilization and scaling practice in the district (not the theoretical one, but the actual one) must be determined if large discrepancies are to be avoided between the estimate and the actual volume removed from the block. This will neces. sitate the collection of data on an actual operation, stump heights, top diameter and log lengths being taken. It is a mistake to accept the regulations issued to foremen as the basis of this work since it is necessary to know the actual practice in the woods. One of the great advantages which the old time cruiser had, was his knowledge of the quantity of lumber a tree would produce. He took into consideration all factors of utilization, scaling and cull. So, if the present day forester wishes to take his estimate out of the realm of chance, he must consider all these various factors of error. Forest mensuration and the law of averages help enormously to eliminate errors of a hidden nature, but they cannot be expected to take care of errors due to careless use or employment of unsuitable tables or curves or ignorance as to utilization and scaling practice.

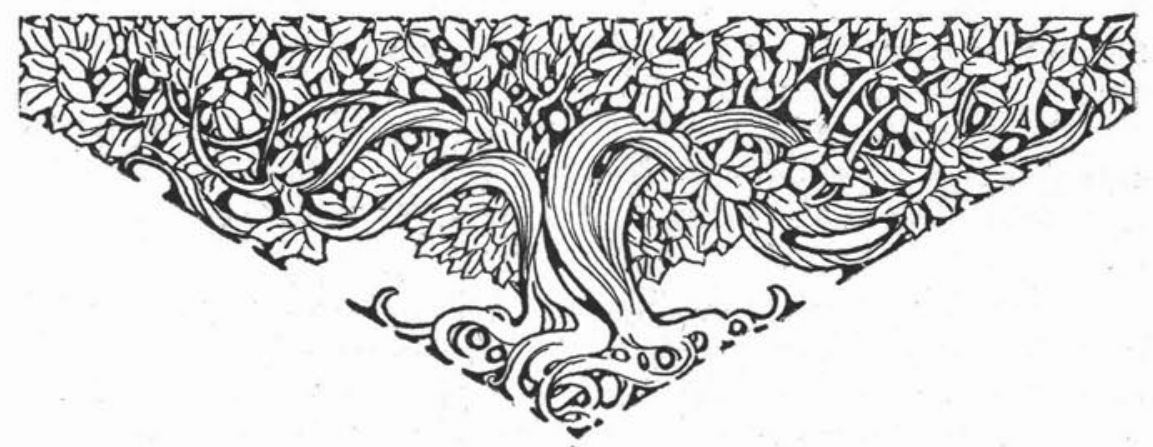

